\title{
Chest Wall Plexiform Fibrohistiocytic Neoplasm
}

National Cancer Institute

\section{Source}

National Cancer Institute. Chest Wall Plexiform Fibrohistiocytic Neoplasm. NCI

Thesaurus. Code C6721.

An intermediate cutaneous fibrohistiocytic neoplasm arising from the chest wall. It is a multinodular poorly circumscribed tumor, characterized by the presence of multinucleated giant cells, mononuclear histiocyte-like cells, and spindle fibroblast-like cells arranged in a plexiform pattern. 